\title{
Profiting From Filesharing: A Measurement Study of Economic Incentives in Cyberlockers
}

\author{
Zubin Jelveh \\ Department of Computer \\ Science and Engineering \\ NYU-Poly, Brooklyn, USA \\ Email: zjelveh@gmail.com
}

\author{
Keith Ross \\ Department of Computer \\ Science and Engineering \\ NYU-Poly, Brooklyn, USA \\ Email: ross@poly.edu
}

\section{INTRODUCTION}

Cyberlockers, or one-click file-hosting services, are a new breed of online businesses which store users' files on remote servers and allow users to access files from any location. The number of cyberlockers has surged since 2006, likely as a function of lowered bandwidth costs and the ease with which cyberlocker services allow users to share copyrighted material like movies, music, applications, games, e-books, and adult content.

After a file is uploaded, the cyberlocker returns a URL with which a user can allow others to access the file. The URLs can be posted and distributed through blogs, discussion forums, Twitter, and YouTube, which are then crawled by Google and cyberlocker-specific search engines like FilesTube. This latter step allows - in effect - anyone to download a shared cyberlocker file.

The primary competitor to cyberlockers in the file-sharing market is the peer-to-peer system BitTorrent. While recent work has shown that there still appears to be more file-sharing traffic on BitTorrent, cyberlocker traffic has grown rapidly and looks to be moving ahead. In fact, as of August 2011, eight out of the top ten file-sharing sites are cyberlockerrelated [8]. There are a number of factors which could explain why file-sharing is a relatively more attractive proposition on cyberlockers.

- Privacy: A user's IP address is potentially identifiable on BitTorrent by crawling a swarm - the group of people connected to a single torrent [1]. On the other hand, the only parties who have access to a cyberlocker user's IP address are the cyberlocker and the user. Since most popular cyberlockers are not located in the United States, the chance that a user's IP address will be handed over to law enforcement or trade groups may be diminished.

- Availability (Diversity): In order to download a file over BitTorrent, there has to be a user who is actively sharing it. But as long as just one person uploaded that file to a cyberlocker and made it publicly available, it's available for download at any time. This would imply that the distribution of available files for download at any moment in time is considerably larger on the cyberlocker platform than on over BitTorrent.
- Availability (Quantity): The number of download sources for any one particular file is larger for cyberlockers than for BitTorrent.

- Speed: The time it takes to download a file over BitTorrent is largely a function of the number of peers who are actively sharing it. But recent work has shown that free cyberlocker downloads are on par with download speeds for BitTorrent and premium downloads are an order of magnitude faster.

As businesses, cyberlockers earn revenue through advertising and the sale of premium accounts, the latter of which offers amenities to users such as greatly improved download speeds, elimination of wait-time for downloads, and extra storage space for files. To attract uploaders to their hostingservice, cyberlockers offer a variety of incentive plans which pay users who upload popular files or convert free users to premium members.

In this paper, we explore the incentive schemes that have been used by cyberlockers, and examine to what extent they have helped to foster the current environment. We first provide an overview of cyberlocker economics. We then crawl three different sites associated with cyberlockers - a search engine, a discussion forum, and a popular cyberlocker site - and analyze the effects of uploader incentives. We found that $(i)$ the fastest growing sites are those that pay uploaders for sharing popular files or for converting free users to premium users; (ii) cyberlockers which abandon incentive systems lose traffic; and (iii) uploaders can earn nontrivial amounts of money from sharing content. These preliminary results establish a strong connection between the success of cyberlockers and the incentive schemes they deploy.

\section{RELATED LiterATURE}

In a study of the characteristics of residential broadband traffic, Maier et al. [4] found that $16 \%$ of HTTP traffic in a large residential European ISP during 2008 and 2009 was accounted for by cyberlocker traffic versus $14 \%$ for P2P applications.

Antoniades et al. [5] studied Rapidshare in 2008 and 2009, which was at the time the most popular cyberlocker. They found that a premium user of the site experienced an order of magnitude improvement in download speeds than a BitTorrent 
user downloading the same file. They also showed that the volume of cyberlocker traffic was greater than the traffic volume of video sites like YouTube.

Sanjuàs-Cuxart et al. [6] monitor the traffic of 50,000 users in a research university in 2009 and find that cyberlocker traffic accounts for $22 \%$ of all HTTP traffic and that the rise of HTTP traffic could mostly be accounted for by two cyberlockers: Rapidshare and Megaupload. The researchers also estimate that a surprisingly high $10 \%$ of Rapidshare users paid for premium accounts.

Mahanti et al. [7] tracked the postings of a popular crime television drama for one season in 2009-10 and found that the postings per episode were far greater on cyberlockers than over BitTorrent. The time to availability was also shorter on cyberlockers as high-bandwidth users could quickly upload the files and make them available. It was also found that premium users on Rapidshare received download speeds which were an order of magnitude greater than free users through the use of fixed throughput throttling. Free users on Megaupload experienced much faster download times as fixed throttling was not enforced. Mahanti also tracked HTTP transactions on a college network between January to December 2009 and found that 13 million of them, representing $4 \%$ of all traffic, was due to cyberlockers. The majority of this traffic was due to premium downloads. Some cyberlockers had a significant amount of premium users while others relied on free users.

To our knowledge, this is the first paper to explore the effects of economic incentive policies on uploaders in the cyberlocker ecosystem.

\section{THE ECONOMICS OF CYBERLOCKERS}

Figure 1 shows the flow of funds through the cyberlocker ecosystem. A file host earns revenue through the sale of premium accounts and the display of advertising on its download pages. Most hosts charge about $\$ 10$ per month for a premium account with discounts offered for signing up for multiple months at a time. The most popular file hosts are ranked among the heaviest-trafficked sites on the web, suggesting that advertising revenues are unlikely to be insignificant. Cyberlockers' primary costs are comprised of the infrastructure and bandwidth investments needed to run sites and the incentive payments to uploaders, also known as "affiliates" in online parlance. The two most popular types of incentive programs are pay-per-download (PPD) and pay-per-sale (PPS). The first rewards uploaders by paying them an amount based on the number of times their files are downloaded, the location of the downloader, and the size of the file.

The pay-per-sale incentive rewards an uploader a percentage of the sale price of a premium account every time a downloader chooses to buy an account after following an uploader's link to a cyberlocker. For example, if a non-account holder lands on the download page for a particular file and chooses to buy a premium account on that same visit, then a percentage of that sale goes to the uploader whose link brought the downloader to the site. The rates can vary from 5 to $65 \%$ of the price of a premium account. Typically uploaders choose
Flow of Funds Through Cyberlocker Ecosystem

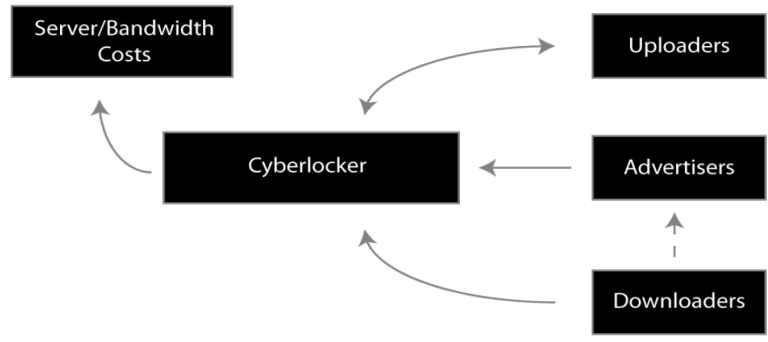

Fig. 1. Each arrow shows the direction in which funds flow in the typical cyberlocker where incentive payments are made to uploaders. The dotted line between Downloaders and Advertisers represents the indirect path through which cyberlockers earn revenue through downloaders.

\begin{tabular}{|c|c|c|c|c|c|}
\hline Date & Counted Downloads / \$ & Premium Sales Count $/ \$$ & Referral \$ & Domain Sales Count / \$ & Total: \\
\hline $2011-05-20$ & $15522 / \$ 110.01$ & $3 / \$ 0$ & $\$ 0$ & $3 / \$ 3.95$ & $\$ 113.96$ \\
\hline $2011-05-21$ & $\underline{18640 / \$ 132.76}$ & $2 / 50$ & $\$ 0$ & $0 / \$ 0$ & $\$ 132.76$ \\
\hline $2011-05-22$ & $10645 / \$ 85.82$ & $2 / \$ 0$ & $\$ 0$ & $1 / \$ 2.75$ & $\$ 88.57$ \\
\hline $2011-05-23$ & $8730 / \$ 67.49$ & 1140 & $\$ 0$ & $1 / \$ 1.75$ & $\$ 69.24$ \\
\hline $2011-05-24$ & $13407 / \$ 105.74$ & 4/\$0 & $\$ 0$ & 4/\$1.8 & $\$ 107,54$ \\
\hline $2011-05-25$ & $15394 / \$ 131.97$ & $3 / 50$ & $\$ 0$ & $2 / \$ 3.2$ & $\$ 135.17$ \\
\hline $2011-05-26$ & $11773 / \$ 98.9$ & $2 / \$ 0$ & $\$ 0$ & $1 / \$ 2.75$ & $\$ 101.65$ \\
\hline $2011-05-27$ & $20543 / \$ 170.38$ & 4/\$0 & $\$ 0$ & $0 / 50$ & $\$ 170,38$ \\
\hline Total: & $114654 / \$ 903.06$ & $21 / \$ 0$ & $\$ 0$ & $12 / \$ 16.2$ & 919.26 \\
\hline
\end{tabular}

Fig. 2. FileSonic earnings screen-shot posted on an online web forum.

whether they want to be paid through a PPD or PPS scheme, they cannot choose both - though some sites have combined plans. Our measurement results in Section 4 strongly suggest it is more valuable for uploaders to select PPS over PPD.

The most likely reason that cyberlockers choose to provide payments for uploading is to attract users to their sites. It appears that the ratio of uploaders to downloaders is quite small, so cyberlockers compete with one another to draw in the most prolific uploaders. This imbalance can be seen from Teh Paradox, a discussion board where uploaders post links to their files. As of July 2011, the section on the board dedicated to movies and television programs has 864,923 messages containing links to cyberlockers. These links were created by just 14,863 users but have generated 172 million views, a ratio of 11,613 views to each uploader.

While it is most likely that a large portion of uploaders do not earn great sums, it appears that more than a few of them have been able to realize sizeable amounts. Figure 2 , taken from a web forum dedicated to the discussion of cyberlockers, shows a screen-shot of the earnings of a prolific FileSonic uploader over an eight day period in May 2011. On an annual basis, the earnings come out to $\$ 41,202$, roughly three times the U.S. minimum wage. More frequently, users posted earnings in the range of $\$ 100$ per week, which, if earned in less developed countries, would provide a substantial source of income. These figures compare favorably to the earnings for workers on Mechanical Turk where only $3 \%$ of respondents reported weekly earnings of over $\$ 50$ [7]. 


\section{Measurement Results for InCentives}

In this paper, we examine to what extent the incentives have helped to foster the current environment, and whether the cyberlocker incentive systems influence uploader activity. To this end, we crawl three different sites associated with cyberlockers - a search engine, a discussion forum, and a popular cyberlocker site - and analyze the effects of uploader incentives.

Recall that FilesTube is a search engine focused on cyberlockers. The first crawl, conducted in June and July 2011, sent search queries for 3,356 movies released since 2006 to the FilesTube search API, resulting in 6.8 million search results containing information on filenames, sizes, the hosting cyberlocker, the web address where FilesTube found the link, and the date the link was added to the index. The second crawl, conducted in July 2011, crawled the Teh Paradox discussion forum where links to files on cyberlockers are posted. The contents of 864,923 threads in the forum's movies and television section where scraped. The third crawl, conducted in January 2012, downloadeded screenshots of earnings posted by uploaders to FileSonic, a populer cyberlocker site.

\section{A. Cyberlocker Search Engine}

From the FilesTube crawl we found that in 2009 three sites comprised the bulk (73\%) of search results: Rapidshare, Megaupload, and Mediafire. This share fell in 2010 (15\%) and $2011(10 \%)$ as a number of other sites gained traction: 4Shared, FileSonic, Fileserve, Hotfile, Oron, and Wupload. Except for 4Shared, all of the new sites offered cash incentives to uploaders of popular content.

Figure 3 shows the number of newly added links by the nine largest cyberlockers since January 2009. It appears that FilesTube only returns results for a set of approved cyberlockers (at the time of this writing there were 47 sites available to be searched). This likely explains the spikes in the chart for sites like FileServe, FileSonic, 4Shared, and HotFile. Once FilesTube added those sites to the approved list, a backlog of search results were added to the index, resulting in an unusually high number of links for that month.

Zooming into the results for Rapidshare (Figure 4), we can see the effect that the removal of the site's incentive system had on uploader activity. In February 2010, the cyberlocker ended its affiliate program which paid uploaders for posting popular content, and in June 2010 it ended an incentive program which offered gifts like free premium accounts. When the incentive programs ended, the number of FilesTube links declined sharply. For the six months prior to the end of the program, there were an average of 18,054 links to files hosted by Rapidshare on FilesTube. That number fell by $67 \%$ to 6,048 for the following six months. The drop-off is even more dramatic $-98 \%$ in the following months - when examining the data from the Teh Paradox crawl (Figure 5).

Interestingly, FilesTube appears to rely largely on three types of web sites for obtaining links for its index. Some cyberlockers like 4Shared allow direct searching of their content and this source comprises a large portion of the search

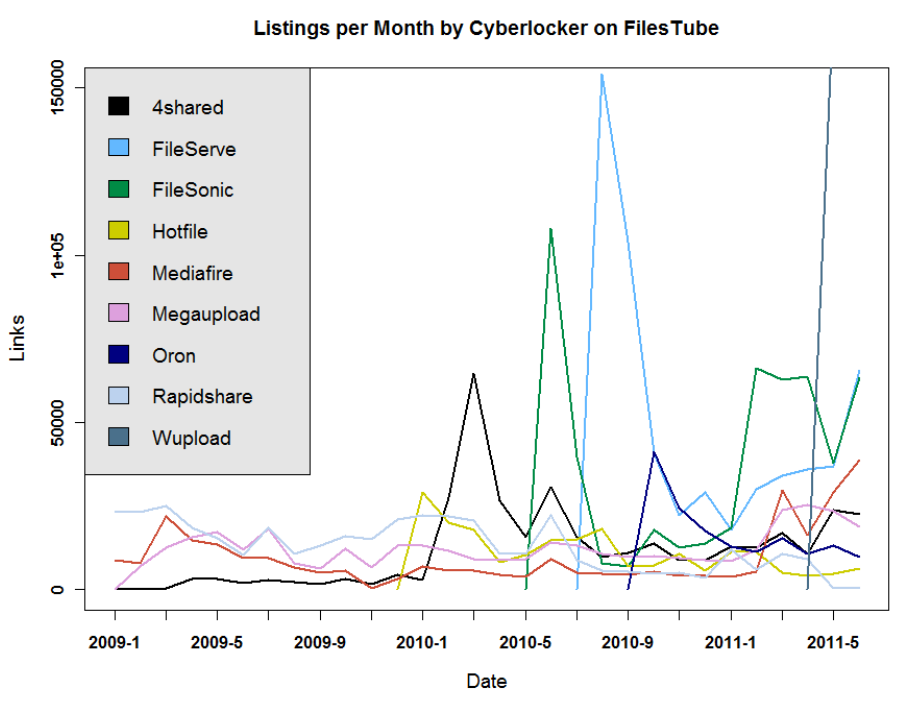

Fig. 3. The number of search results by cyberlocker for the movies queried on FilesTube.

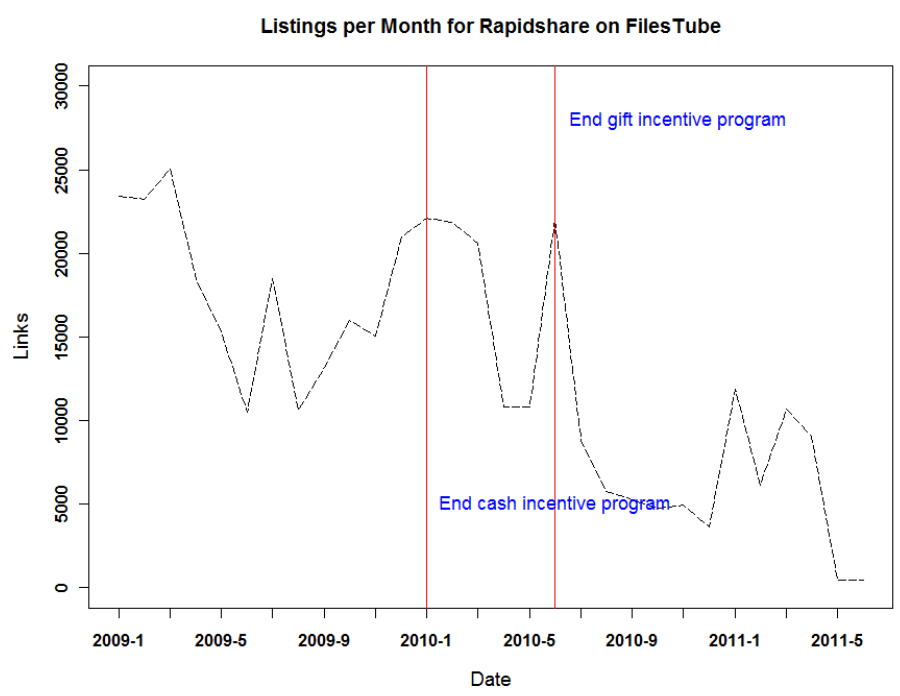

Fig. 4. According to search results on FilesTube, it appears that the removal of uploader incentive programs reduced uploader on activity on Rapidshare.

results found in the crawl. The other two major sources of links were blogs and web discussion forums. Figure 6 shows the types of web sites which comprise the top 20 sources of links for FilesTube. Roughly $45 \%$ of crawled links originated from cyberlockers, $50 \%$ from web forums, and $5 \%$ from blogs.

\section{B. Cyberlocker Discussion Forum}

Teh Paradox is one of the largest forums dedicated to the posting of cyberlocker links. It claims 1.9 million members who have generated 1.7 million threads. Figures 7 and 8 show the monthly number of threads and views, respectively, for the seven top cyberlockers on the site. Unsurprisingly, there is a large correlation between threads and views for each 


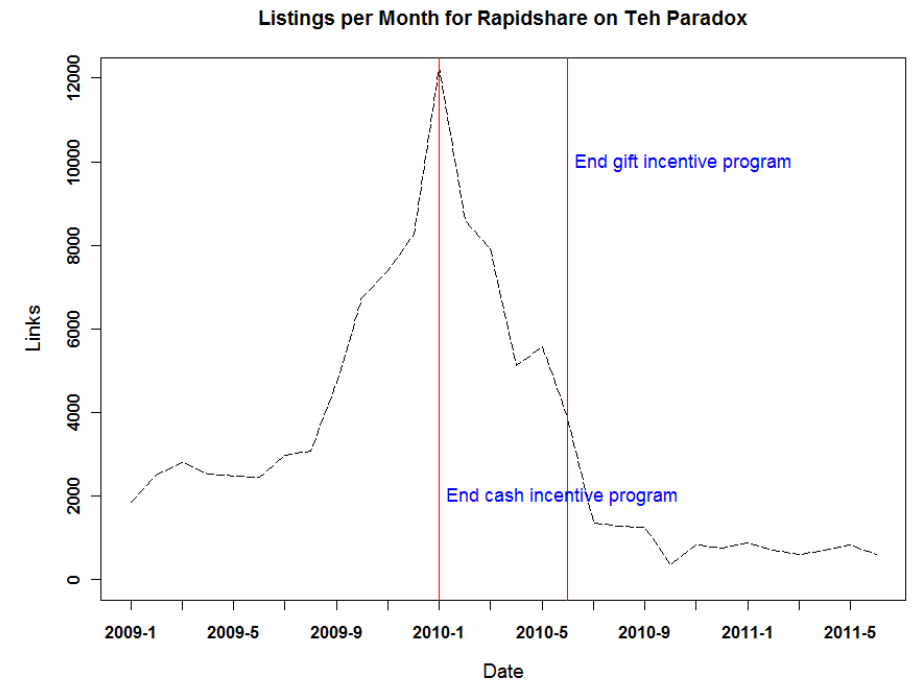

Fig. 5. The number of listings on Teh Paradox forum which include a link for a Rapidshare file. There is a significant drop off following the termination of incentives.

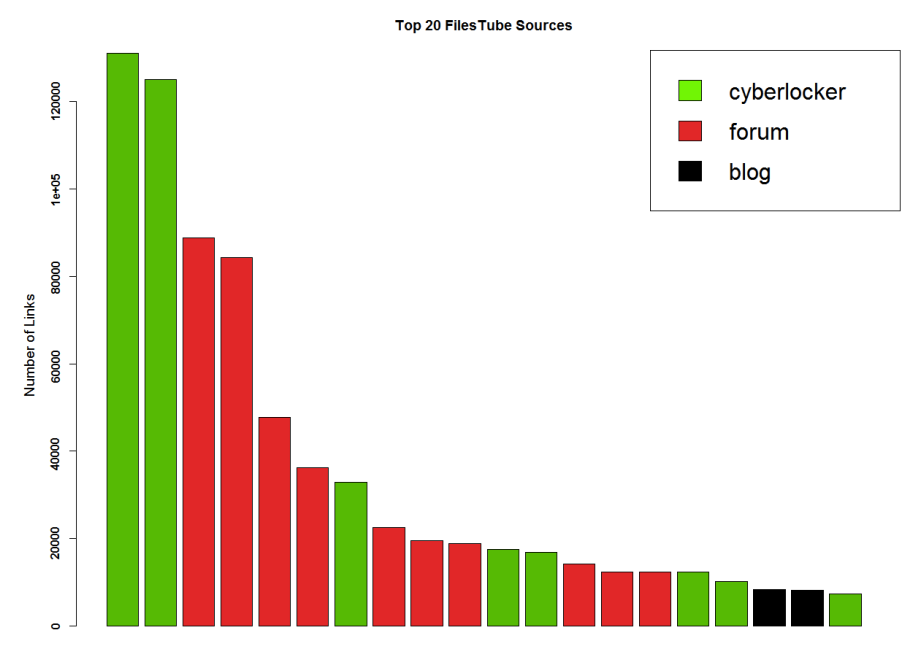

Fig. 6. The top 20 sources of links on FilesTube by type of source. Eight come from cyberlockers, ten from forums, and two from blogs. The number of links range from 0 to about 120,000 .

cyberlocker. Importantly, we see that the sites with incentive programs are seeing large gains in exposure, while nonincentive sites are experiencing a drop-off in popularity.

\section{Uploader Earnings}

One of the more innovative aspects of the cyberlocker business is the cash payments made to uploaders who share popular content or convert free users to premium users. To understand the distribution of uploader earnings, we crawled an online web forum where users posted screenshots of their earnings from sharing links on FileSonic. We were able to collect a sample of roughly 1,000 screenshots, but the results

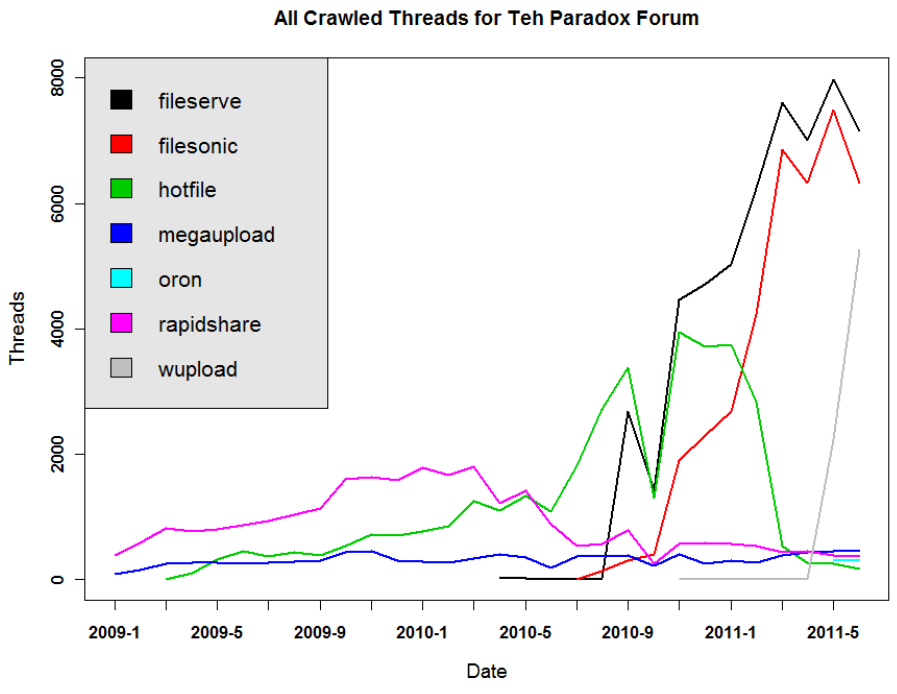

Fig. 7. The number of threads which contained a link for a particular cyberlocker on the movie section of Teh Paradox forum.

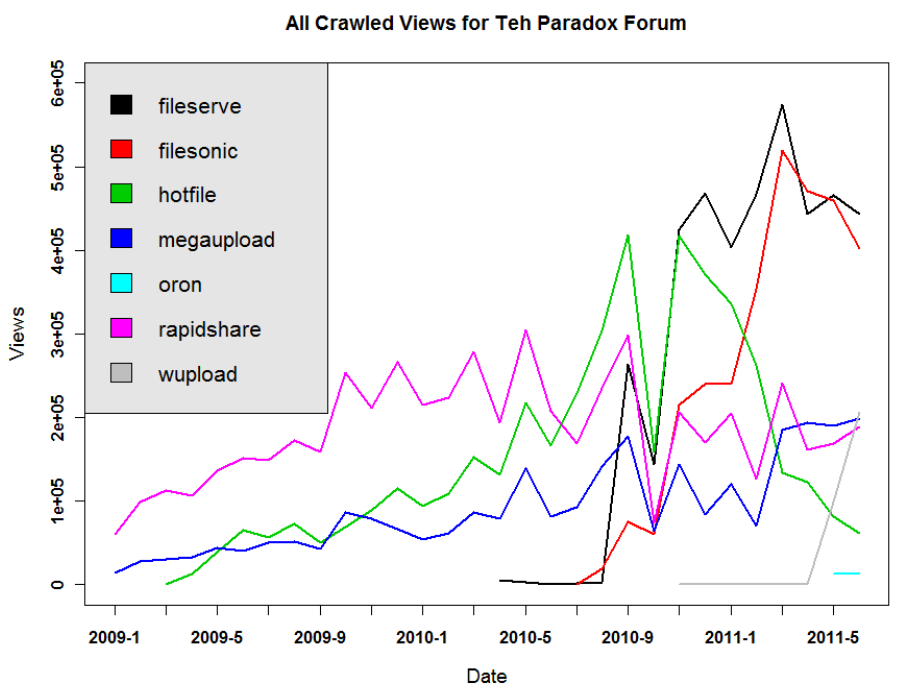

Fig. 8. The number of pageviews for threads which contained a link for a particular cyberlocker on the movie section of Teh Paradox forum.

shared below are a sub-sample of 151 of these screenshots. There are obvious sample selection issues related to who decides to post their earnings, but these statistics should give us a sense of the earnings potential of cyberlocker uploaders.

The earnings screenshots (similar to one shown in Figure 2) reveal the daily earnings of FileSonic uploaders. The 151 screenshots captured 2,653 days worth of earnings information. Figure 9 shows the distribution of daily earnings. The average amount earned per day was $\$ 33.69$ with a maximum of $\$ 226.27$ and a minimum of $\$ 0.00$. Assuming these amounts could be earned over an entire year, the average uploader in this sample would earn $\$ 12,298.45$ over 365 days and the best 
Distribution of Daily Earnings

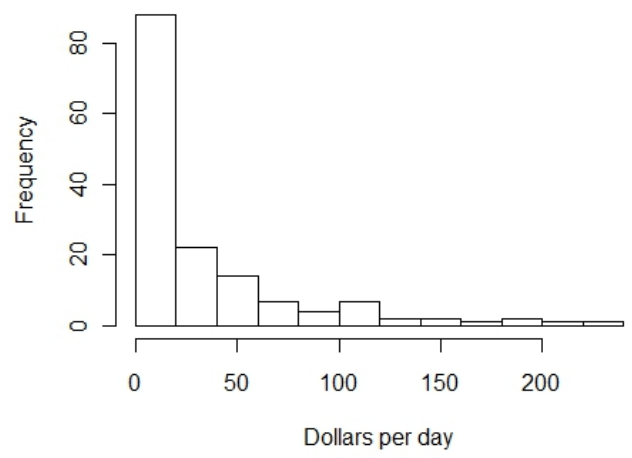

Fig. 9. The average daily earnings of uploaders who posted their earnings on a web forum.

uploader would earn $\$ 82,589.11$ over 365 days. It's not known in which countries uploaders are based. The average earnings presented here are below poverty levels in countries like the United States and those in Western Europe, but would put a person in a relatively high income bracket of India or China.

The earnings screenshots also indicate which incentive plan a FileSonic uploader selected. Of the 151 screentshots, 75 show that the uploader chose the pay-per-download plan while 76 showed that the uploader chose the pay-per-sale plan. The average earnings for those who chose PPD was $\$ 21.12$ versus $\$ 46.10$ for PPS. This would suggest that cyberlockers tend to place more value on uploaders who can entice free users to sign up for premium accounts rather than uploaders who post popular content. Of those who select the PPD plan, the average number of downloads per day was 1,060 and the average earnings per download was $\$ 0.015$. Based on the rate card shown in Figure ??, this suggests that downloaders are primarily from groups in the lower-left part of the size-country matrix.

\section{CONCLUSION}

This short paper presented a prelimary economic analysis of incentives in cyberlockers based on measurement results from three different types of sites related to cyberlockers. We found:

- The fastest growing cyberlockers in terms of links posted on FilesTube and Teh Paradox forum are those which offer incentive plans.

- The end of incentive plans at Rapidshare was followed by a major drop-off in uploader activity on that site. The number of Rapidshare links on FilesTube fell by $67 \%$ in the months after the plans were terminated. Rapidshare links fell by $95 \%$ on the Teh Paradox forum.

- It is possible for uploaders on FileSonic to earn sizeable amounts from their activities. The average daily earnings for those who posted screenshots on a web forum was
$\$ 33.69$ with one uploader reporting earnings of $\$ 226.27$ per day.

- FileSonic places a higher value on uploaders who can entice downloaders to buy premium memberships rather than uploaders who post popular files. The average earnings for uploaders who chose the pay-per-sale incentive scheme was $\$ 46.10$ versus $\$ 21.12$ for those who chose the pay-per-download scheme.

We can conclude that cyberlocker incentive plans have indeed fostered the current cyberlocker environment and have significantly influenced uploader behavior.

Cyberlockers have come under much scrutiny in 2012 after one of the largest such businesses, MegaUpload, was shut down by the United States Justice Department [9] and its owners were indicted for "massive worldwide online piracy" generating revenues of $\$ 175$ million. Immediately following the MegaUpload shutdown many other leading cyberlockers disabled either their sharing functionalities, their incentive systems, or both, effectively shutting themselves down. Still, other cyberlockers saw surges in traffic suggesting that many file sharers were not dissuaded by the potential threat of legal action. In future work, we plan to survey the uploaders to these cyberlockers in order to gain a better understanding of the demographics and motivations of this population.

\section{REFERENCES}

[1] Antoniades, D., Markatos, E., and Dovrolis, C. One-click hosting services: A file-sharing hideout. In Proc. ACM SIGCOMM Internet Measurement Conference (IMC) (2009).

[2] LeBlond, S., Zhang, C., Legout, A., Ross, K.W., and Dabbous, W. I know where you are and what you are sharing: exploiting P2P communications to invade users' privacy. Internet Measurement Conference (IMC) (2011).

[3] Maier, G., Feldmann, A., Paxson, V., AND Allman, M. On dominant characteristics of residential broadband internet traffic. In Proc. ACM IMC (2009).

[4] Mahanti, A., Williamson, C., Carlsson, N., Arlitt, M., and Mahanti, A. Characterizing the file hosting ecosystem: A view from the edge. 29th International Symposium on Computer Performance, Modeling, Measurements and Evaluation (2011).

[5] MegaUpload alternatives see surge in traffic after shutdown. Torrent $F$ reak.[Online]. Available: http://torrentfreak.com/megaupload-alternativessee-surge-in-traffic-after-shutdown-120126/

[6] Ross, J., Irani, L., Silberman, M. S., Zaldivar, A., and Tomlinson, B. . Who are the crowdworkers?: shifting demographics in mechanical turk. In CHI EA 10: Proceedings of the 28th of the international conference extended abstracts on Human factors in computing systems (2010).

[7] Sanjuàs-Cuxart, J., Barlet-Ros, P., and Solé-Pareta, J. Measurement based analysis of one-click file hosting services. In Journal of Network and Systems Management (2009).

[8] Top-10 Largest file-sharing sites. TorrentFreak.[Online]. Available: http://torrentfreak.com/top-10-largest-file-sharing-sites-110828/

[9] U.S. Dept. of Justice. Justice department charges leaders Of Megaupload with widespread online copyright infringement. [Online]. Available: http://www.justice.gov/usao/vae/news/2012/01/20120119megauuploadnr.html 